\title{
INVESTIGACIÓN
}

\section{Digestion and absorption of olive oil}

\author{
By Beatriz Bermúdez, Yolanda M. Pacheco, Sergio López, Rocío Abia and Francisco J.G. Muriana*
}

\author{
Cellular and Molecular Nutrition, Instituto de la Grasa, \\ Consejo Superior de Investigaciones Científicas, Seville, Spain \\ "Corresponding author: Dr. Francisco J.G. Muriana. Tel: +93 954611550 \\ Email: muriana@ig.csic.es
}

\section{CONTENTS}

1. INTRODUCTION

2. BRIEF DESCRIPTION OF OLIVE OIL COMPOSITION

3. OLIVE OIL AND GASTROINTESTINAL FUNCTIONS

3.1. Digestion of triglycerides in the stomach and olive oil on gastric acid secretion

3.2. Digestion of triglycerides and other lipids in the duodenum and olive oil on small intestine secretion

3.3. Absorption of olive oil monoglycerides and free fatty acids in the duodenum

3.4. Intracellular re-synthesis of triglycerides in the enterocytes

3.5. Absorption of olive oil minor compounds in the intestine

3.6. Assembly of intestinal lipoproteins containing olive oil triglycerides and minor compounds

\section{ACKNOWLEDGMENTS}

REFERENCES

\section{RESUMEN}

\section{Digestión y absorción del aceite de oliva.}

El aceite de oliva es una grasa monoinsaturada (rica en ácido oleico), compuesta por triglicéridos (>98\%) y componentes menores. En los procesos de digestión y absorción de los triglicéridos participan enzimas y se producen cambios fisicoquímicos. La lipasa gástrica es el componente mayoritario de la actividad lipolítica gástrica en humanos. La hidrólisis de los triglicéridos continúa en el duodeno, por la acción sinérgica de las lipasas gástrica y sobretodo pancreática, y la secreción de las sales biliares. Mediante la lipólisis en el estómago se hidrolizan entre el 10 y el $30 \%$ de los triglicéridos, produciéndose diglicéridos (DG) y ácidos grasos libres (FFA). Esto facilita la emulsión lipídica y la acción posterior de la lipasa pancreática, que preferentemente hidroliza los enlaces éster en las posiciones 1 y 3 de los triglicéridos y/o DG, generando 2-monoglicéridos (2-MG). Los diferentes metabolitos lipídicos (FFA y 2-MG) se absorben rápidamente por las células epiteliales del intestino delgado, donde también se absorben la mayoría de los compuestos menores (carotenos y polifenoles, entre otros) del aceite de oliva (virgen extra).

Con respecto a dietas ricas en ácidos grasos poliinsaturados, el aceite de oliva reduce la secreción ácida gástrica y estimula la liberación de la colecistoquinina, indicando que el consumo de aceite de oliva puede ser beneficioso en las enfermedades digestivas.

PALABRAS-CLAVE: Aceite de oliva; Ácidos grasos monoinsaturados; Compuestos menores; Digestión gástrica e intestinal; Absorción gástrica e intestinal; Dieta Mediterránea

\section{SUMMARY}

\section{Digestion and absorption of olive oil.}

Olive oil is a monounsaturated (oleic acid)-rich fat, mainly constituted by triglycerides (>98\%) and minor compounds. As other macronutrients, dietary triglyceride digestion and absorption are a complex processes involving enzyme activities and physicochemical changes. In humans, hydrolysis of olive oil triglycerides begins in the stomach where it is catalyzed by an acid-stable gastric lipase. Triglyceride hydrolysis continues in the duodenum, by the synergetic actions of gastric and colipase-dependent pancreatic lipases and bile secretion. Gastric lipolysis leads to the hydrolysis of $10-30 \%$ of ingested triglycerides, generating mainly diglycerides (DG) and free fatty acids. This facilitates subsequent triglyceride hydrolysis by pancreatic lipase by allowing fat emulsification. Pancreatic lipase cleaves the sn-1 and sn-3 positions of triglycerides and/or DG obtaining sn-2 monoglycerides. Different lipid metabolites are quickly absorbed along the epithelial cells of the small intestine, acting olive oil as a supplier of oleic-acid-rich hydrocarbon skeletons for cellular synthesis of triglycerides and phospholipids. Absorption of mostly minor compounds of (extra virgin) olive oil takes place in the small intestine, as native or derivatives.

Compared to diets rich in polyunsaturated fatty acids, olive oil suppresses gastric acid secretion and is a potent releasing factor of cholecystokinin peptide, which consistently indicate that the consumption of olive oil might be beneficial in digestive diseases.

KEY-WORDS: Olive oil; Monounsaturated fatty acids; $\mathrm{Mi}$ nor compounds; Gastric and intestinal digestion; Gastric and intestinal absorption; Mediterranean diet.

\section{INTRODUCTION}

The Mediterranean diet has become a cultural model for dietary improvement. Different countries and regions on the Mediterranean basin have their own dietary traditions, but in all of them (extra virgin) olive oil occupies a central position. Recent data suggest that its components may have a greater role in diseases prevention than previously thought.

According to EC Regulation no. 1638/98 OJEC 210 of 28/7/98, virgin olive oils are those obtained from the fruit of the olive tree by mechanical 
processes or other physical processes, in conditions, especially thermal ones, that do not cause alterations in the oil which must not receive any treatment other than washing, decantation, centrifugation and filtering. This category does not include oils that have been obtained by using solvents or by a re-esterification process or any other mixture with oils of different characteristics. Virgin olive oil is a natural product, with no additives or preservatives, a real "fruit juice" compared with the majority of vegetables, which are extracted from ground oily seeds.

Olive oil can be consumed in the natural state known as extra and/or virgin olive oil, or as a refined product. Extra virgin olive oil is a virgin olive oil whose free acidity, expressed as oleic acid, is not more than 1 gram per 100 grams and organoleptic characteristics (flavour and colour) are excellent. Virgin and refined oils differ little in fatty acid composition. Oleic acid (18:1n-9), a monounsaturated fatty acid (MUFA), is the main component of olive oil. The levels of fatty acids vary during the different maturation stage of the olives, the variety and the growing conditions. It is generally accepted that cooler areas will give oil with higher monounsaturated content than warmer climates. The proportion of linoleic acid $(18: 2 n-6)$ in oils from warmer regions tends to be higher.

Virgin and refined oils differ in the composition of the minor compounds that could range from one to $3 \%$. The constituents of minor compounds are present in low concentrations but they are responsible for the unique and delicate flavour of extra virgin olive oil (aldehydes, alcohols, esters, hydrocarbons, ketones, furans and others). This fraction contains important bioactive compounds such as $\alpha$-tocopherol (with vitamin E activity) and B-caroten (which functions as vitamin A).

Extra virgin olive oil in the diet also guarantees the intake of phenolic antioxidants. The amount of phenolics in olive oil depends on several factors, including cultivar (olives from the Coratina variety are the richest in phenolics), degree of maturation, possible infestations and climate (Brenes et al., 1999; Boskuo et al., 2000). The procedure for (extra virgin) olive oil obtaining has also influence on the content in phenolic compounds (Di Giovacchino et al., 1994).

The processes by which triglycerides (three fatty acids bound to a glycerol backbone) and minor compounds from (extra virgin) olive oil are digested and/or absorbed in the gastrointestinal tract will be the matter of reviewing in this issue.

\section{BRIEF DESCRIPTION OF OLIVE OIL COMPOSITION}

Olive oil is a vegetable fat which main difference with other oils is its high content in MUFA. Oleic acid
Table 1

Composition of fatty acids and molecular species of triglycerides in olive oil (adapted from Abia et al., 1999)

\begin{tabular}{|c|c|c|}
\hline \multirow{9}{*}{$\begin{array}{l}\text { Fatty acid } \\
(\mathrm{mol} / 100 \mathrm{~mol})\end{array}$} & $16: 0$ & 12.8 \\
\hline & $18: 0$ & 2.7 \\
\hline & $18: 1 n-9$ & 71.9 \\
\hline & $18: 2 n-6$ & 5.6 \\
\hline & $18: 3 n-3$ & 0.7 \\
\hline & Others & 6.3 \\
\hline & SFA & 16.3 \\
\hline & MUFA & 77.5 \\
\hline & PUFA & 6.4 \\
\hline \multirow{12}{*}{$\begin{array}{l}\text { Triglycerides }^{1} \\
(\mathrm{~mol} / 100 \mathrm{~mol})\end{array}$} & LLL & 0.01 \\
\hline & OLL/OOLn & 0.14 \\
\hline & PLL/POLn & 0.20 \\
\hline & OOL & 4.05 \\
\hline & POL & 1.17 \\
\hline & PPL/PSLn & 0.05 \\
\hline & PPPo & 0.01 \\
\hline & 000 & 61.96 \\
\hline & $\mathrm{POO}$ & 29.35 \\
\hline & PPO/PLS & 1.02 \\
\hline & SOO & 1.82 \\
\hline & POS & 0.16 \\
\hline
\end{tabular}

1 Nomenclature of fatty acids: $P$, palmitic acid, hexadecaenoic acid,16:0; O, oleic acid, cis-9 octadecenoic acid,18:1 n-9; L, linoleic acid, cis-9,12 octadecadienoic acid, 18:2n-6; S, stearic acid, octodecaenoic acid, 18:0; Po, Palmitoleic acid, cis-9 hexadecenoic acid, 16:1n-9; Ln, $\alpha$-linolenic acid, cis-9, 12, 15 octadecatrienoic acid, 18:3 n-3.

2 Nomenclature of triglycerides: LLL, sn-glycerol-linoleate-linoleate-linoleate; OLL, sn-glycerol-oleate-linoleate-linoleate; OOLn, sn-glycerol-oleate-oleate-linolenate; PLL, sn-glycerolpalmitate-linoleate-linoleate; POLn, sn-glycerol-palmitate-oleatelinolenate; OOL, sn-glycerol-oleate-oleate-linoleate; POL, snglycerol-palmitate-oleate-linoleate; PPL, sn-glycerol-palmitate-palmitate-linoleate; PSLn, sn-glycerol-palmitate-stearate-linolenate; PPPo, sn-glycerol-palmitate-palmitate-palmitoleate; OOO, sn-glycerol-oleateoleate-oleate; $\mathrm{POO}$, sn-glycerol-palmitate-oleate-oleate; PPO, snglycerol-palmitate-palmitate-oleate; PLS, sn-glycerol-palmitate-linoleatestearate; SOO, sn-glycerol-stearate-oleate-oleate; POS, sn-glycerolpalmitate-oleate-stearate. 
concentration ranges from 56 to $84 \%$ of total fatty acids. Linoleic acid, the major essential fatty acid and the most abundant polyunsaturated fatty acid (PUFA) in our diet, is present in concentrations between $3-21 \%$ in olive oil (Boskuo et al., 2000). Almost all fatty acids are complexed in the form of triglycerides (saponifiable fraction, 98\%) (Table 1).

The unsaponifiable fraction of olive oil contains highly bioactive compounds that are present in minor concentrations (Table 2). Despite their wide variety and nutritional significance, they commonly account up to $1.5 \%$ of the total oil composition (reaching individual concentrations as smaller as ppm) (Mataix, 1999). This fraction is fundamental in contributing to specific characteristics of (extra virgin) olive oil, such as its oxidative stability and its special flavour (aroma and taste) as well as its colour (carotenoids and chlorophylls among pigments) (Mateos et al., 2003). It is important to note that only virgin olive oil contains minor compounds, since mostly of them disappear during refining processes (Rastrelli et al., 2002).

Phenolics that can be found in (extra virgin) olive oil are classified into simple ones (hydroxytyrosol, tyrosol, vanillic acid, vanilline, cafeic acid, cynamic acid, $p$-coumaric acid, o-coumaric acid, ferulic acid and phenylacetic acid, among others); conjugated ones (secoroids or aglycons of hydroxytyrosol and tyrosol); flavones (luteolin and apigenin); and lignans (pinoresinol, acetoxypinoresinol). Figure 1 represents the most abundant phenolic compounds

Table 2

Minor compounds (extra virgin) olive oil (adapted from Mataix, 1999)

\begin{tabular}{|c|c|}
\hline Minor compounds & Concentration (ppm) \\
\hline Terpens & 3,500 \\
\hline Sterols & 2,500 \\
\hline Hydrocarbons & 2,000 \\
\hline Squalene & 1,500 \\
\hline Phenolics & 350 \\
\hline$\beta$-carotene & 300 \\
\hline Aliphatic alcohols & 200 \\
\hline Tocopherols & 150 \\
\hline Esters & 100 \\
\hline Aldehydes and cetones & 40 \\
\hline
\end{tabular}

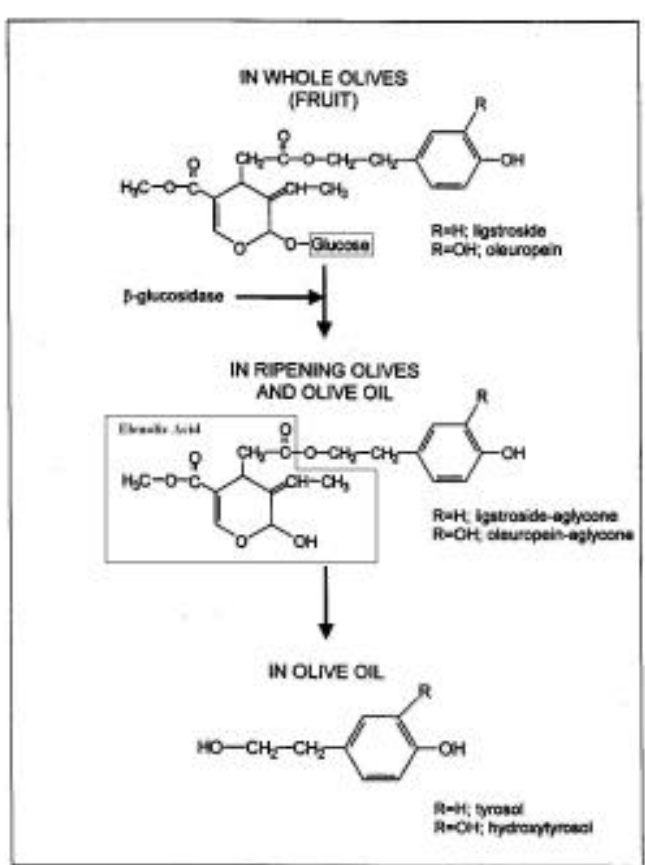

Figure 1

Major phenolic compounds in (extra virgin) olive oil (adapted from Vissers et al., 2001).

in (extra virgin) olive oil, which are the non-polar oleuropein- and ligstroside- aglycones and their derivatives. These aglycones are formed during ripening of olive fruits by enzymatic removal of glucose from their respective oleuropein and ligstroside glycosides. Further degradation of aglycones generates simple phenolic compounds as hydroxytyrosol and tyrosol, respectively (Owen et al., 2000).

The major carotenoids in (extra virgin) olive oil are lutein and B-carotene, but also traces of lycopene (Su et al., 2002). B-carotene has antioxidant properties, but also functions as a precursor of vitamin $A$ that is very important in maintenance of the eye tissues and other differentiated tissues (of epithelial origin), and in reproduction (Olmedilla et al., 2001).

Vitamin $E$ in olive oil includes a group of four tocopherols and four tocotrienols of which $\alpha$-tocopherol is the most abundant in the nature and has the highest biological activity (Herrera and Barbas, 2001). They constitute the first defence line against oxidants.

Other minor compounds of olive oil can be mentioned because of their importance in the cholesterol metabolism, such as B-sitosterol that decreases the absorption of cholesterol in mammals, and squalene (a hydrocarbon) that is an intermediate of the cholesterol biosynthesis pathway and a major component of lipids in human skin. 


\section{OLIVE OIL AND GASTROINTESTINAL FUNCTIONS}

The digestion and absorption of olive oil saponifiable fraction, as dietary triglycerides, is a dynamic complex and very efficient process that is only partially understood at the molecular level. The hydrophobicity of lipids is a limiting factor for the digestion because of hydrophilic character of lipases.

\subsection{Digestion of triglycerides in the stomach and olive oil on gastric acid secretion}

The first event in the transformation of insoluble oil into soluble and absorbable lipids is the formation of an initial emulsion (chyme) by mastication in the mouth where the dispersion of triglycerides happens. The surface area of dietary lipids is then increased, which benefits their emulsion (formation of lipid droplets) in the stomach. During the initial gastric process, partially emulsified triglycerides are attached by lingual and gastric lipases that are similar enzymes in structure and physicochemical characteristics (Ramirez et al., 2001). The activity of these lipases towards short-chain, medium-chain and long-chain fatty acids is not the same. For instance, the lipolytic activity of gastric lipase is three times higher on medium-chain triglycerides (MCT) than on long-chain triglycerides (LCT). The major digestion products of the gastric phase are diglycerides (DG) and free fatty acids (FFA). Lingual and gastric lipases preferentially hydrolyze the $s n-3$ ester bond resulting in formation of $s n-1,2 \mathrm{DG}(\mathrm{Mu}$ and Hoy, 2004).

Gastric lipase activity does not contribute to phospholipids (PL) and cholesterol esters (CE) hydrolysis, and is functional in the $\mathrm{pH}$ range of 3 to 6 . In the human stomach, this enzyme hydrolyzes only 10 to $30 \%$ of ingested triglycerides because of an inhibition process induced by the long-chain FFA generated, which are mostly protonated at gastric $\mathrm{pH}$. It explains the limited lipolysis of triglycerides under gastric conditions regarding the complete triglycerides hydrolysis by pancreatic lipase in the duodenum (Armand et al., 1999). The presence of long-chain FFA per se is not inhibitory of lipolysis, since oleic acid in amounts close to, or even higher than those generated during physiological gastric lipolysis, does not alter the kinetics of triolein hydrolysis by gastric lipase (Pafumi et al., 2002).

During gastric lipolysis FFA have higher affinity for the surface than the core of the lipid droplets (Pafumi et al., 2002). There is a considerable fusion between lipid droplets, probably due to the presence of FFA, monoglycerides (MG), and DG that are known to be fusiogenic. This change in the lipid composition of the droplet surface during lipolysis could modify the interfacial tension or the surface pressure and consequently interfere with gastric lipase binding and activity (Gargouri et al., 1987). The accumulation of FFA at the droplet surface leads to an inhibition of lipolysis by gastric lipase. The mechanism by which this happens is attributed to the formation of clusters at the surface of the lipid droplets. Isolation of these clusters has permitted to know that they are particles of about $200 \mathrm{~nm}$ mainly composed primarily of FFA (approximately $74 \%$ ), as well as PL (16\%), MG $(5 \%)$, DG $(4 \%)$, free cholesterol (1\%), triglycerides $(<1 \%)$, and gastric lipase. The role of olive oil with regard to other dietary oils on the prevention of surface particle formation to extend the effectiveness of gastric lipolytic activity should be further studied.

In 1886, in what was probably the first study to investigate the influence of dietary fat on gastric function, Ewald and Boas observed that the addition of olive oil to a test meal suppressed gastric acid secretion. Since then, numerous studies have confirmed this finding by the presence of olive oil in different segments of the intestinal tract. Intraduodenal administration of olive oil reduces gastric secretion in animals (Brzozowski et al., 1998) and in humans (Serrano et al., 1997), when compared to dietary PUFA. Oleic acid itself has gastro-protective actions against acute injury of gastric mucosa in animals (West et al., 2003) and in humans (Konturek et al., 1998). It is associated with the release of several peptides in plasma, including cholecystokinin (CCK), secretin, tyrosine-tyrosine peptide $Y Y$, and with the suppression of plasma gastrin. These observations consistently indicate that the consumption of olive oil might be beneficial in digestive diseases (gastric or duodenal ulcers), where the attenuation of gastric acid secretion is a key therapeutic goal.

\subsection{Digestion of triglycerides and other lipids in the duodenum and olive oil on small intestine secretion}

As digestion is advancing, the pylorus closes and the antrum contracts forcefully grinding solid particles. This contraction causes the antral contents moved back from the terminal antrum into the corpus. Both actions, grinding and retro-propulsion of antral contents, provide most of mechanical action involved in the pre-intestinal emulsification of triglycerides (Shen et al., 2001). These processes are an important requisite for efficient hydrolysis by pancreatic lipase in the duodenum.

Lipid emulsion enters the intestine as fine droplets less than $0.5 \mu \mathrm{m}$ in diameter (Shen et al., 2001). The smaller size increases proportionally the lipid surface exposed to pancreatic lipase (Blow, 1991). The fatty acids released from the initial gastric lipolysis and the amino acids and peptides formed by gastric proteolytic activity stimulate specific receptors in intestinal epithelial cells to secrete CCK. 
It stimulates gallbladder contraction delivering bile salts to the duodenum. The fats droplets covered with bile salts are not accessible to pancreatic lipase, but the co-lipase enzyme allows the pancreatic lipase molecule to bind to the lipid aqueous interface and facilitates the stabilization of emulsified triglycerides.

Digestion of triglycerides is mostly caused by pancreatic lipase, which is released from the pancreatic tissue into the duodenum upon the hormonal response to CCK. Pancreatic lipase has an optimum $\mathrm{pH} 8$, being inactive at $\mathrm{pH}$ lower than 6 . It is a 449 amino acids peptide with a high degree of structural homology with other lipases. All lipases share the pentapeptide Gly-X-Ser-X-Gly as a catalytic site, but analysis of three-dimensional structure of pancreatic lipase shows a folding of the molecule on itself that hides this active site (Lowe, 1997). Pancreatic lipase acts on insoluble triglyceride substrate and has to adsorb to the oil--water interface to carry out the catalytic step of the enzymatic lipolysis reaction. Pancreatic lipase does not remain irreversibly adsorbed to the oil--water interface, and instead can exchange rapidly between oil droplets (Kaiker et al., 2004). This suggests the existence of equilibrium between soluble and lipid-bound PL. In addition to pancreatic lipase, pancreatic acinar cells synthesize two pancreatic lipase related proteins (PLRP1 and PLRP2). PLRP1 has not known activity, and PLRP2 differs with a normal lipase in substrate specificity, behaviour on bile salts and dependence on co-lipase (Lowe, 2002). Pancreatic lipase cleaves the $s n-1$ and $s n-3$ positions of triglycerides obtaining sn-2 MG and FFA (Ros, 2000; Mu and Hoy, 2004). sn-2 MG can isomerise to sn-1 MG in an aqueous medium, but it rarely occurs as the absorption of sn-2 $M G$ is very fast.

Oleic acid is the most potent releasing factor of CCK from the small intestine into the blood, which means that the consumption of olive oil contributes to regulate the physiological pancreatic and bile secretions (Yago et al., 1997; Krzeminski et al., 2003). Oleic acid is also a powerful liberating of pancreatic polypeptide (PP). In addition, intra-ileal oleic acid inhibits gastric and small intestinal motility possibly via increased plasma levels of peptide $Y Y$ and enteroglucagon (Ohtani et al., 2001).

\subsection{Absorption of olive oil monoglycerides and free fatty acids in the duodenum}

Absorption of lipid molecules takes place along the epithelial cells of the small intestine, mainly in the proximal jejunum but also in parts that are more distal. The epithelial cells of the small intestine show an apical membrane with a brush border made up of many microvilli, which have a width of about $100 \mathrm{~nm}$ and being much smaller $(5-20 \mathrm{~nm})$ the spaces between them. Lipid metabolites generated throughout the digestion of olive oil (sn-2 MG and FFA) are more polar than the parent triglycerides, but they still have a limited solubility in the aqueous environment of the intestinal lumen. Hofmann and Borgstrom $(1962 ; 1964)$ discovered the importance of their micellar solubilization for their intestinal absorption. Micelles are small particles (3-6 nm) containing molecules of bile salt and present a sterol or fat-soluble portion and a polar group. The micelle aggregates $s n-2 \mathrm{MG}$ and FFA in its middle while exposes the polar ends of the bile salts, enabling solution in water. The detergent properties of bile salts allow the micelles to approach sn-2 MG and FFA to the brush border of the enterocyte along the unstirred water layer (with a thickness of $50-500 \mu \mathrm{m}$ ) (Wilson et al., 1971).

However, there are also non-micellar mechanisms to lipid absorption. When the emulsion droplets shrink during lipolysis, liquid crystalline structures of unilamellar and multilamellar vesicles or liposomes of $s n-2 M G$ and FFA are extruded. They are formed continuously, but quickly dissolved into micelles at the appropriate bile salt concentrations (Hernell et al., 1990). It likely replenishes mixed micelles that have lost lipids during the process of absorption by enterocytes. This happens when the concentration of bile salts in the lumen exceeds the critical micellar concentration (3-5.4 mM), forming larger and disc-shaped particles with a hydrodynamic radius of about $200 \AA$ (even 400-600 $\AA$ if the amount of lipid further increases) (Carey et al., 1983). On the other hand, it is also possible to find sub-micellar aggregates including cholesterol and lysophospholipids (Shoemaker and Nichols, 1990).

Today is well known that micelles and liposomes coexist in the intestinal lumen, but since they are constantly exchanging $s n-2$ MG and FFA, their relative roles in lipid transport are still unclear (Shen et al., 2001). Lipid carrying particles able to arrive to the unstirred water layer cannot be larger than the width of the gaps in the microvilli themselves. Micelles and sub-micelles are the main vehicles for approximating sn-2 MG and FFA successfully to the membrane of the microvilli. There, the acidic microclimate $(\mathrm{pH}$ 5.3-6) promotes both micellar dissociation and fatty acid protonation, facilitating the passive diffusion of FFA across the cellular membrane (Shiau and Levine, 1980). Enterocytes may also take up FFA via energy dependent and carrier-mediated processes. A fatty acid binding protein (FABP) is present in the apical and lateral areas of the villus (in the region of the tight junction) and in the crypt (Stremmel, 1988). This carrier plays an important role at low FFA concentrations (probably to ensure sufficient uptake of lipid nutrients), whereas passive diffusion predominates at high FFA concentrations. Other proteins, including 
GP330 (megalin), CD36, SR-BI and caveolin can bind lipids and related metabolites (Abumrad et al., 2000). These transporters are localized into the brush border membrane and highly expressed by diets rich in fats, with highest expression in jejunum, duodenum and ileum, in this order. Interestingly, other potential binding proteins with specificity for long-chain FFA have been cloned in adipocytes (Shaffer and Lodish, 1994) and in the small intestine (FATP4) (Hermann et al., 1999).

Differences in the rate of absorption of FFA have been described as a function of chain length and of number and place of double bonds ( $\mathrm{Mu}$ and Hoy, 2004). Short-chain (2-4 C) and medium-chain (6-12 C) fatty acids are more rapidly absorbed than fatty acids of more than 14 carbon atoms, because they do not need micellar solubilization, just bound to albumin and are transported directly to the liver by the portal vein (Ramirez et al., 2001). Furthermore, the degree of unsaturation facilitates the solubilization and absorption.

The positional distribution of fatty acids in dietary triglycerides determines whether fatty acids are absorbed as FFA or sn-2 MG. It has been shown a linear correlation between the presence of linoleic acid at the sn-2 position (but not in other stereospecific positions) of triglyceride molecule and the plasma level of arachidonic acid (20:4n-6), indicating that only $s n-2$ position is maintained throughout the absorption and remaining metabolic processes (Renaud et al., 1995). In olive oil, up to $95 \%$ of total fatty acids at the $s n-2$ position are MUFA, mainly oleic acid, which means that olive oil acts as a supplier of oleic acid-rich hydrocarbon skeletons for cellular synthesis of triglycerides and phospholipids (Abia et al., 1999).

\subsection{Intracellular re-synthesis of triglycerides in the enterocytes}

FABP binds FFA and transports them within the enterocyte to the smooth endoplasmic reticulum, where enzymes of lipid synthesis are located. It is known the existence of two FABP isotypes: I-FABP and L-FABP, which differ in their binding specificity. I-FABP binds strongly to FFA, whereas L-FABP preferentially binds to $s n-2 M G$ and other ligands (Storch and Thumser, 2000).

Triglyceride re-synthesis begins with the activation of FFA to acyl-CoA. In this form, fatty acids are sequentially transferred to $s n-2 \mathrm{MG}$ by $M G$ and DG acyltransferases. These enzymes form a complex called "triglyceride synthetase" (Lehner and Kuksis, 1995), and the pathway favours the stereospecific reacylation at the $s n-1$ position. It contributes to $80 \%$ of the intestinal triglyceride re-synthesis in the fed state. On the other hand, acyl-coA can also be transferred to $\alpha$-glycerophosphate (derived from glucose metabolism) by the phosphatidic acid pathway, which accounts for the remaining $20 \%$ (Mu and Hoy, 2004). Therefore, the amount of FFA in the enterocyte is the limiting factor for triglyceride re-synthesis. The relative importance of the MG acyltransferase and $\alpha$-glycerophosphate pathways depends on the supply of $s n-2 \mathrm{MG}$.

The regulation of triglyceride re-synthesis is complex and involves transcriptional and post-transcriptional steps that respond to specific hormones, metabolites (derived from individual meals and long-term diet exposures), fasting and re-feeding cycles, and exercise- mediated energy expenditure (Coleman and Lee, 2004). A high dietary level of MCT may slow the re-synthesis of triglycerides and the formation of lipoproteins, since the fatty acids they supply are directly transported to the liver by the portal vein (Mu and Hoy, 2004). LCT, particularly those carrying long-chain PUFA of $n-3$ family, also reduce the re-synthesis of triglycerides by competitive and inhibitory effects of eicosapentaenoyl-CoA with other acyl-CoA and DG acyltransferases, respectively (Berge et al., 1999). These effects are a part of a cascade of events, firstly initiated by inhibiting the activation of LXR (liver $X$ receptors), which further activates SREBP-1 (sterol regulatory element binding protein-1), a directly activator of genes for fatty acids and glycerolipid synthesis (Ou et al., 2001). SFA (stearic acid) has not inhibitory effect on LXR, whereas unsaturated fatty acids promote different levels of inhibitory effect: oleic acid<linoleic acid $<\alpha$-linolenic acid $=$ arachidonic acid .

\subsection{Absorption of olive oil minor compounds in the intestine}

A recent review highlighted the numerous gaps existing in the knowledge of the metabolism of fat-soluble bioactive compounds and the factors that affect their absorption (Borel, 2003). There are controversial studies about absorption of (extra virgin) olive oil phenolic compounds. Simple phenols can be absorbed in the intestine, but few data on phenolic derivatives are available. A major problem in studying the absorption of phenolics in humans is their degradation by microorganisms in the colon, which result in an overestimation of the absorbed amount when faecal excretion is measured (Scalbert and Williansom, 2000). Another problem is that complex phenolics are not commercially available and studies using individual compounds are not possible.

Structure of phenolics has a major impact on the mechanisms of intestinal absorption. The most widely discussed structural parameters are molecular weight, glycosylation and esterification 


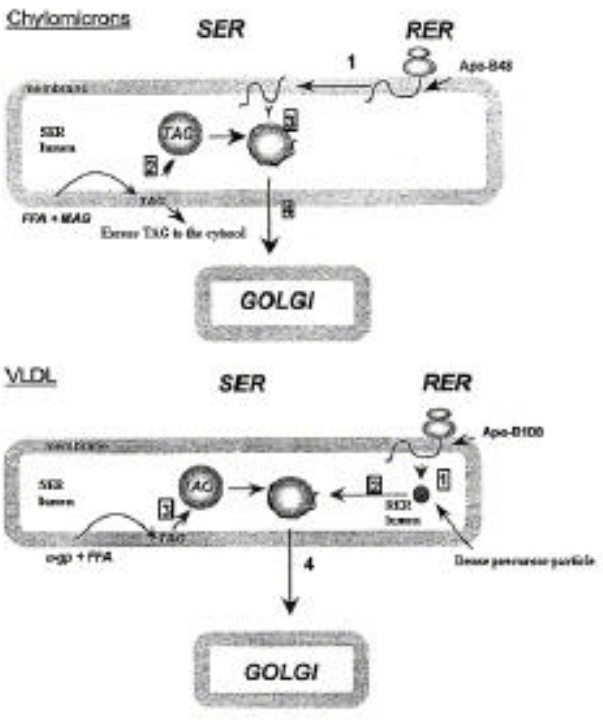

Figure 2

Assembly models for intestinal lipoproteins (adapted from Cartwright et al., 2000). TAG, triglycerides.

(Scalbert et al., 2002). It has been described a passive diffusion through the lipid bilayer of the epithelial cell membrane for the more polar phenolics (hydroxytyrosol and tyrosol) (Manna et al., 2000), whereas larger molecules as derivatives glycosides could be absorbed via a glucose transporter (Hollman et al., 1999). Since urine metabolites from these molecules are hydroxytyrosol and tyrosol, it is also possible the hydrolysis of glycosylated molecules in the gastrointestinal tract before absorption or in the intestinal cell, blood or even in the liver after absorption, as well as could occur to oleuropein and ligstroside aglycons (Vissers et al., 2002) (Figure 3). It is not demonstrated non-enzymatic de-glycosylation in the

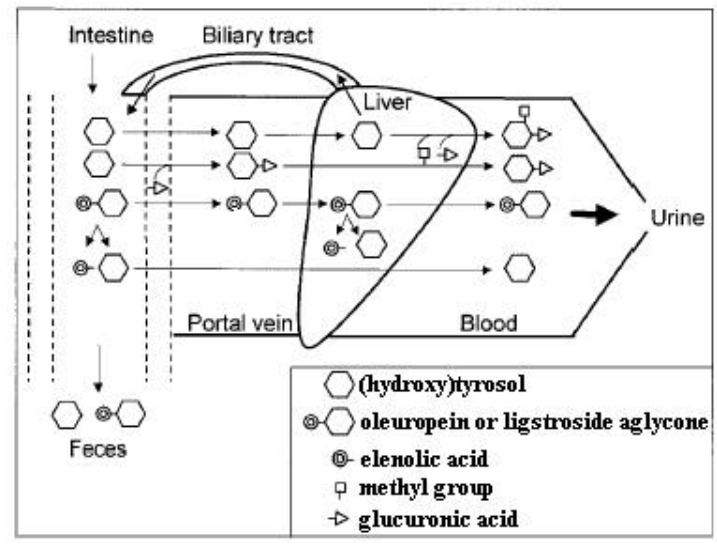

Figure 3

Possible metabolic routes of (extra virgin) olive oil phenolics (adapted from Vissers et al., 2002). human body (Gee et al., 1998). However, cells of gastrointestinal mucosa can produce, and the colon microflora secrete, active B-glucosidases (Scalbert and Williamson, 2000).

Absorption of mostly phenolics takes place in the small intestine, as recently shown in subjects with ileostomy (Vissers et al., 2002). Additional absorption can be produced in colon (Williamson et al., 2000; Hollman and Katan, 1998), some studies indicating that this process will occur if phenolic compounds are partially degraded by the colonic microflora (Scalbert and Williamson, 2000). According to an in vivo model, hydroxytyrosol and tyrosol are absorbed in a dose-dependent and non-saturable fashion in humans (Vissioli et al., 2000); whereas there is a bidirectional passive diffusion mechanism when hydroxytyrosol is up taken in vitro by human intestinal Caco-2 cells (Manna et al., 2000).

A determinant factor in the bioavailability of carotenoids is their liberation from the food matrix and dissolution in the lipid phase (Parker, 1996). Indeed, carotenoids are better absorbed when ingested from oils (extra virgin olive oil) than from fruits and vegetables (De Pee and West, 1996). Physiologic doses of carotenoids may passively diffuse in the intestinal mucosa but, at least, there is one carrier-mediated transport in Caco-2 cells for lutein (Reboul et al., 2003). However, B-carotene can be converted into vitamin A in the intestinal mucosa, contrary to lutein, which is apparently absorbed without molecular changes (Olmedilla et al., 2001).

Absorption mechanisms of $\alpha$-tocopherol (vitamin E) are poorly documented. The gastric emptying of $\alpha$-tocopherol follows that of lipids (Borel et al., 2001), what is not surprising since it is fat-soluble. There are no major metabolic changes of $\alpha$-tocopherol from (extra virgin) olive oil in the human stomach, but enterocytes are responsible for its absorption. After intestinal absorption, $\alpha$-tocopherol is also packaged into chylomicrons $(\mathrm{CM})$, they are further secreted into the systemic circulation though the lymphatic vessels (Herrera and Barbas, 2001).

\subsection{Assembly of intestinal lipoproteins containing olive oil triglycerides and minor compounds}

The small intestine can secrete two different triglyceride-rich lipoproteins: $\mathrm{CM}$ and very low-density lipoproteins (VLDL). CM are formed after fat feeding, whereas VLDL are the major lipoproteins secreted during fasting (Mu and Hoy, 2004).

Intestinal cell culture systems (e.g. human Caco-2 cells) are extensively used to study the formation and secretion of lipoproteins. Although several questions remain unclear, most of the cellular mechanisms involved in the intestinal 
assembly of triglyceride-rich lipoproteins have been recently described (Cartwright et al., 2000). Major cellular compartments of the enterocyte where assembly takes place are rough and smooth endoplasmic reticulum (RER and SER), as well as Golgi apparatus. Furthermore, newly synthesised apo B-48 and triglycerides accumulate in the SER membrane and are transferred into the lumen in a microsomal triglyceride transfer protein (MTP)dependent step. There are some differences between CM and VLDL assembly and once formed they remain in separate vesicles without mixing, until they are finally secreted into the lymph (Figure 2).

The main difference in the assembly models for CM and VLDL is that for VLDL assembly there is the formation of an intermediate precursor: a little and dense apo B-rich particle that later fuse with triglyceride-rich and apo B-deficient particles to form the lipoprotein. Another difference is that for CM assembly there is a critical rate-limiting step with the transfer of triglycerides and apo B-48. However, rate-limiting steps in the VLDL assembly include the movement of apo B-100 into the RER lumen, dense particles from the RER to the SER lumen, and possibly the formation of the triglyceride-rich particles. In the latest step, both models coincide. It means that new lipoproteins move to Golgi cisternae and vesicles to be prepared for exocytose through the plasma membrane, with limited mixing of particles sizes. The secretion takes place through the basolateral membrane of enterocytes and lipoproteins enter the lymphatic capillaries of intestinal microvilli that drain into lymphatic channels, reaching the systemic circulation through the thoracic duct. VLDL are found into the lymph during fasting (there is a continuous secretion), whereas $\mathrm{CM}$ secretion is only induced in the postprandial state (VLDL secretion is then saturated). Studies involving lipid infusion in animals and lipid interaction in the in vitro model of human intestinal cells have shown that phospholipids and triglycerides induce the formation of VLDL and CM, respectively (Mu and Hoy, 2004). A sequential assembly model for CM involves three independent events: assembly of primordial lipoproteins, synthesis of triglycerides-rich lipid droplets, and core expansion and synthesis of nascent lipoproteins by fusing primordial lipoproteins with lipid droplets (Hussain, 2000).

It has been suggested that the absorption of phenolics in humans does not occur through a pathway dependent on CM formation, although phenolic compounds greatly contributes to enhance antioxidant plasma capacity during the postprandial phase (Bonanome et al., 2000). On the other hand, carotenoids seems to be exclusively transported into lipoproteins and considerable amounts of different carotenoids, such as B-carotene, have been detected in human $\mathrm{CM}$ after their ingestion as an oleoresin (Perez-Galvez et al., 2003) and as direct vegetables and fruits (Cardinault et al., 2003). Importantly, ß-carotene is better incorporated into $\mathrm{CM}$ when ingested in a meal containing LCT than in a meal containing only MCT (Borel et al., 1998). It suggests that absorption of carotenoids from or in the presence of (extra virgin) olive oil may be highly improved. Therefore, (extra virgin) olive oil dually acts as natural supplier and as a co-factor for carotenoids absorption, which is of particular major importance in vitamin A deficiency.

\section{ACKNOWLEDGMENTS}

The authors would like to acknowledge to the Ministry of Education and Science (ECl) of the Spanish Government for supporting this manuscript (grant AGL2001-0584). Beatriz Bermúdez and Sergio López are supported by I3P and FPU fellowships, whereas Yolanda M. Pacheco has an I3P Post-Doctoral contract from ECl.

\section{REFERENCES}

Abia, R., Perona, J.S., Pacheco, Y.M., Montero E., Muriana, F.J.G., Ruiz-Gutierrez, V. (1999). Postprandial triacylglycerols from dietary virgin olive oil are selectively cleared in humans. J. Nutr., 129, 2184-2191.

Abumrad, N.A., Sfeir, Z., Connelly, M.A., Coburn, C. (2000). Lipid transporters: membrane transport systems for cholesterol and fatty acids. Curr. Opin. Clin. Nutr. Metab. Care, 3, 255-262.

Armand, M., Pasquier, B., Andre, M., Borel, P., Senft, M., Peyrot, J., Salducci, J., Portugal, H., Jaussan, V., Lairon, D. (1999). Digestion and absorption of 2 fat emulsions with different droplet sizes in the human digestive tract. Am. J. Clin. Nutr., 70, 1096-1106.

Berge, R.K., Madsen, L., Vaagenes, H., Tronstad, K.J., Gottlicher, M., Rustan, A.C. (1999). In contrast with docosahexaenoic acid, eicosapentaenoic acid and hypolipidaemic derivatives decrease hepatic synthesis and secretion of triacylglycerol by decreased diacylglycerol acyltransferase activity and stimulation of fatty acid oxidation. Biochem. J., 343, 191-197.

Blow, D. (1991). Lipases reach the surface. Nature, 351, 444-445.

Bonanome, A., Pagnan, A., Caruso, D., Toia, A., Xamin, A., Fedeli, E., Berra, B., Zamburlini, A., Ursini, F., Galli, G. (2000). Evidence of postprandial absorption of olive oil phenols in humans. Nutr. Metab. Cardiovasc. Dis., 10, 111-120.

Borel, P., Tyssandier, V., Mekki, N., Grolier, P., Rochette, Y., Alexandre-Gouabau, M.C., Lairon, D., Azais-Braesco, V. (1998). Chylomicron B-carotene and retinyl palmitate responses are dramatically diminished when men ingest $B$-carotene with medium-chain rather than long-chain triglycerides. J. Nutr., 128, 1361-1367.

Borel, P., Pasquier, B., Armand, M., Tyssandier, V., Grolier, P., Alexandre-Gouabau, M.C., Andre, M., Senft, M., Peyrot, J., Jaussan, V., Layron, D., Azais-Braesco, V. (2001). Proccessing of vitamin $A$ and $E$ in the human gastrointestinal tract. Am. J. Physiol. Gastrointest. Liver Physiol., 280, G95-G103. 
Borel, P. (2003). Factors affecting intestinal absorption of highly lipophilic food microconstituents (fat-soluble vitamins, carotenoids and phytosterols). Clin. Chem. Lab. Med., 41, 979-994.

Boskou, D., Simopoulos, A., Visioli, F. (2000). Olive oil in Mediterranean diets. World Rev. Nutr. Diet, 87, 56-77.

Brenes, M., Garcia, A., Garcia, P., Rios, J.J., Garrido, A. (1999). Phenolic compounds in Spanish olive oils. J. Agric. Food Chem., 47, 3535-3540.

Brzozowski, T., Konturek, P.C., Konturek, S.J., Kwiecien, S., Pajdo, R., Brzozowska, I., Hahn, E.G. (1998). Involvement of endogenous cholecystokinin and somatostatin in gastroprotection induced by intraduodenal fat. J. Clin. Gastroenterol., 27, S125-S137.

Cardinault, N., Tyssandier, V., Grolier, P., Winklhofer-Roob, B.M., Ribalta, J., Bouteloup-Demange, C., Rock, E., Borel, P. (2003). Comparison of the postprandial chylomicron carotenoid responses in young and older subjects. Eur. J. Nutr., 42, 315-323.

Carey, M.C., Small, D.M., Bliss, C.M. (1983). Lipid digestion and absorption. Annu. Rev. Physiol., 45, 651-677.

Cartwright, I.J., Plonné, D., Higgins, J.A. (2000). Intracellular events in the assembly of chylomicrons in rabbit enterocytes. J. Lipid Res., 41, 1728-1739.

Coleman, R.A., Lee, D.P. (2004). Enzymes of triacylglycerol synthesis and their regulation. Progr. Lipid Res., 43, 134-176.

De Pee, S., West, C.E. (1996). Dietary carotenoids and their role in combating vitamin A deficiency: a review of the literature. Eur. J. Clin. Nutr., 53, S38-S53.

Di Giovacchino, L., Solinas, M., Miccoli, M. (1994). Effect of extraction system on the quality of virgin olive oil. J. Am. Oil Chem. Soc., 71, 1189-1194.

Gargouri, Y., Pieroni, G., Ferrato, F., and Verger, R. (1987). Human gastric lipase. A kinetic study with dicaprin monolayers. Eur. J. Biochem., 169, 125-129.

Gee, J.M., Dupont, M.S., Rhodes, M.J.C., Johnson, I.T. (1998). Quercetin glucosides interact with the intestinal glucose transport pathway. Free Radic. Biol. Med., 25, 19-25.

Haiker, H., Lengsfeld, H., Hadvary, P., Carriere, F. (2004). Rapid exchange of pancreatic lipase between triacylglycerol droplets. Biochim Biophys Acta, 1682, 72-79.

Hermann, T., Buchkremer, F., Gosh, I., Hall, A.M., Bernlohr, D.A, Stremmel, W., Coe, N.R., Smith, A.J., Frohnert, B.I., Watkins, P.A., Bernlorh D.A. (1999). The fatty acid transport protein (FATP1) is a very long chain acyl-CoA synthetase. J. Biol. Chem., 274, 36300-36304.

Hernell, O., Staggers, J.E., Carey, M.C. (1990). Physical-chemical behaviour of dietary and biliary lipids during intestinal digestion and absorption. 2. Phase analysis and aggregation states of luminal lipids during duodenal fat digestion in healthy adult human beings. Biochemistry, 29, 2041--2056.

Herrera, E., Barbas, C. (2001). Vitamin E: action, metabolism and perspectives. J. Physiol. Biochem., 57, 43-56.

Hofmann, A.F., Borgstrom, B. (1962). Physico-chemical state of lipids in intestinal content during their digestion and absorption. Fed. Proc., 21, 43-50.

Hofmann, A.F., Borgstrom, B. (1964). The intraluminal phase of fat digestion in man: the lipid content of the micellar and oil phases of intestinal content obtained during fat digestion and absorption. J. Clin. Invest., 43, 247-257.

Hollman, P.C., Katan, M.B. (1998). Absorption, metabolism and bioavailability of flavonoids. In: Flavonoids in health and disease. Rice-Evans C.A. and Packer L., eds., pp. 483-522. Marcell Decker, New York, NY.
Hollman, P.C., Buysman, M.N., Van Gameren, Y., Cnossen, E.P., de Vries J.H., Katan, M.B. (1999). The sugar moiety is a major determinant of the absorption of dietary flavonoid glycosides in man. Free Radic. Res., 31, 569-573.

Hussain, M.M. (2000). A proposed model for the assembly of chylomicrons. Atherosclerosis, 148, 1-15.

Konturek, J.W., Hengst, K., Konturek, S.J., Sito, E., Stachura, J., Domschke, W. (1998). Physiological role of cholecystokinin in gastroprotection in humans. Am. J. Gastroenterol., 93, 2385-2390.

Krzeminski, R., Gorinstein, S., Leontowicz, H., Leontowicz, M., Gralak, M., Czerwinski, J., Lojek, A., Ciz, M., Martin-Belloso, O., Gligelmo-Miguel, N., Trakhtenberg, S. (2003). Effect of different olive oils on bile excretion in rats fed cholesterol-containing and cholesterol-free diets. J. Agric. Food Chem., 51, 5774-5779.

Lehner, R., Kuksis, A. (1995). Triacylglycerol synthesis by purified triacylglycerol synthetase of rat intestinal mucosa. Role of acyl-CoA acyltransferase. J. Biol. Chem. 270, 13630-13636.

Lowe, M.E. (1997). Structure and function of pancreatic lipase and colipase. Ann. Rev. Nutr., 17, 141-158.

Lowe, M.E. (2002). The triglyceride lipases of the pancreas. J. Lipid Res., 43, 2007-2016.

Manna, C., Galletti, P., Maisto, G., Cucciolla, V., DAngelo, S., Zappia, V. (2000). Transport mechanism and metabolism of olive oil hydroxytyrosol in Caco-2 cells. FEBS Lett., 470, 341-344.

Mataix, J. (1999). Aceite de Oliva Virgen: nuestro patrimonio alimentario. Ed. Universidad de Granada, Puleva Food.

Maetos, R., Domínguez, M.M., Espartero, J.L., Cert, A. (2003). Antioxidant effect of phenolic compounds, alpha-tocopherol, and other minor components in virgin olive oil. J. Agric. Food Chem., 51, 7170-7175.

Mu, H., Hoy, C.E. (2004). The digestion of dietary triacylglycerols. Prog. Lipid Res., 43, 105-133.

Ohtani, N., Sasaki, I., Naito, H., Shibata, C., Matsuno, S. (2001). Mediators for fat-induced ileal brake are different between stomach and proximal small intestine in conscious dogs. J. Gastrointest. Surg., 5, 377-382.

Olmedilla, B., Granado, F., Blanco, I. (2001). Carotenoides y Salud Humana. Ed. Fundación Española de la Nutrición.

Ou, J., Tu, H., Shan, B., Luk, A., DeBose-Boyd, R.A., Bashmakov, Y., Goldstein, J.L., Brown, M.S. (2001). Unsaturated fatty acids inhibit transcription of the sterol regulatory element binding protein-1c (SREBP-1c) gene by antagonizing ligand-dependent activation of the LXR. Proc. Natl. Acad. Sci., 98, 6027-6032.

Owen, R.W., Mier, W., Giacosa, A., Hull, W.E., Spiegelhalder, B., Bartsch, H. (2000). Phenolic compounds and squalene in olive oils: the concentration and antioxidant potential of total phenols, simple phenols, secoroids, lignans and squalene. Food Chem. Toxicol., 38, 647-659.

Pafumi, Y., Lairon, D., de la Porte, P.L., Juhel, C., Storch, J., Hamosh, M., Armand, M. (2002). Mechanisms of inhibition of triacylglycerol hydrolysis by human gastric lipase. J. Biol. Chem., 277, 28070-28079.

Parker, R.S. (1996). Absorption, metabolism, and transport of carotenoids. FASEB J., 10, 542-551.

Perez-Galvez, A., Martin, H.D., Sies, H., Stahl, W. (2003). Incorporation of human carotenoids from paprika oleoresin into human chylomicrons. Br. J. Nutr., 89, 787-793. 
Ramirez, M., Amate, L., Gil, A. (2001). Absorption and distribution of dietary fatty acids from different sources. Early Human Develop., 65, S95-S101.

Rastrelli, L. Passi, S., Ippolito, F., Vacca, G., De Simone, F. (2002). Rate of degradation of alpha-tocopherol, squalene, phenolics, and polyunsaturated fatty acids in olive oil during different storage conditions. J. Agric. Food. Chem., 50, 5566-5570.

Reboul, E., Abou, L., Mikail, C., Ghiringhelli, O., Andre, M., Gleize, B., Kaloustian, J., Portugal, H., Amiot, M. (2003). Lutein is apparently absorbed by a carrier-mediated transport process in Caco-2 cells. Clin. Nutr., 22, S103.

Renaud, S.C., Ruf, J.C., Petithory, D. (1995). The positional distribution of fatty acids in palm oil and lard influences their biologic effects in rats. J. Nutr., 125, 229-237.

Ros, E. (2000). Intestinal absorption of triglyceride and cholesterol. Dietary and pharmacological inhibition to reduce cardiovascular risk. Atherosclerosis, 151, 357-379.

Scalbert, A., Williamson, G. (2000). Dietary intake and bioavailability of polyphenols. J. Nutr., 130, 2073S-2085S.

Scalbert, A., Morand, C., Manach, C., Rémésy, C. (2002). Absorption and metabolism of polyphenols in the gut and impact on health. Biomed. Pharmacother., 56, 276-282.

Serrano, P., Yago, M.D., Mañas, M., Calpena, R., Mataix. J., Martinez-Victoria, E. (1997). Influence of type of dietary fat (olive and sunflower oil) upon gastric acid secretion and release of gastrin, somatostatin, and peptide YY in man. Dig. Dis. Sci., 42, 626-633.

Shaffer, J.E, Lodish, H.F. (1994). Expression cloning and characterization of a novel adipocyte long chain fatty acid transport protein. Cell, 79, 427-436.

Shen, H., Howles, P., Tso, P. (2001). From interaction of lipidic vehicles with intestinal epithelial cell membranes to the formation and secretion of chylomicrons. Adv. Drug Deliv. Rev., 50, S103-S125.

Shiau, Y.F., Levine, G.M. (1980). pH dependence of micellar diffusion and dissociation. Am. J. Physiol., 239, G177-G182.
Shoemaker, D.C., Nichols, J.W. (1990). Hydrophobic interaction of lysophospholipids and bile salts at submicellar concentrations. Biochemistry, 29, 5837-5842.

Storch, J., Thumser, A.E. (2000). The fatty acid transport function of fatty acid-binding proteins. Biochim. Biophys. Acta, 1486, 28-44.

Stremmel, W. (1988). Uptake of fatty acids by jejunal mucosal cells is mediated by a fatty acid binding membrane protein. J. Clin. Invest., 82, 2001-2010.

Su, Q., Rowley, K.G., Itsiopoulus, C., ODea, K. (2002). Identification and quantitation of major carotenoids in selected components of the Mediterranean diet: green leafy vegetables and olive oil. Eur. J. Clin. Nutr., 56, 1149-1154.

Visioli, F., Galli, C., Bornet, F., Mattei, A., Patelli, R., Galli, G., Caruso, D. (2000). Olive oil phenolics are dose-dependently absorbed in humans. FEBS Lett., 468, 159-160.

Vissers, M.N, Zock, P.L., Roodenburg, A.J.C., Leenen, R., Katan, M.B. (2002). Olive oil phenols are absorbed in humans. J. Nutr., 132, 409-417.

West, S.D., Helmer, K.S., Chang, L.K., Cui, Y., Greeley, G.H., Mercer, D.W. (2003). Cholecystokinin secretagogue-induced gastroprotection: role of nitric oxide and blood flow. Am. J. Physiol. Gastrointest. Liver Physiol., 284, G399-G410.

Williamson, G., Day, A.J., Plumb, G.W., Couteau, D. (2000). Human metabolic pathways of dietary flavonoids and cinnamates. Biochem. Soc. Trans., 28, 16-22.

Wilson, F.A., Sallee, V.L., Dietschy, J.M. (1971). Unstirred water layers in intestine: rate determinant of fatty acid from micellar solutions. Science, 174, 1031-1033.

Yago, M.D., Gonzalez, M.V., Martinez-Victoria, E., Mataix, J., Medrano, J., Calpena, R., Perez, M.T., Manas, M. (1997). Pancreatic enzyme secretion in response to test meals differing in the quality of dietary fat (olive and sunflower seed oils) in human subjects. Br. J. Nutr., 78, 27-39. 